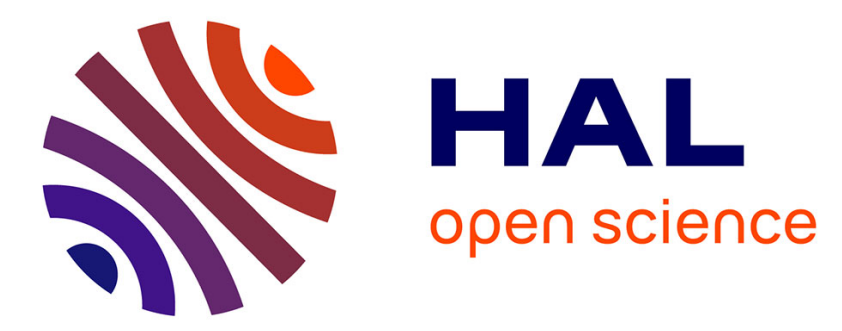

\title{
Multi-reactive surfactant and miniemulsion Atom Transfer Radical Polymerization: An elegant controlled one-step way to obtain dextran-covered nanocapsules
}

Laura Marcela Forero Ramirez, Jérôme Babin, Marc Schmutz, Alain Durand, Jean-Luc Six, Cécile Nouvel

\section{To cite this version:}

Laura Marcela Forero Ramirez, Jérôme Babin, Marc Schmutz, Alain Durand, Jean-Luc Six, et al.. Multi-reactive surfactant and miniemulsion Atom Transfer Radical Polymerization: An elegant controlled one-step way to obtain dextran-covered nanocapsules. European Polymer Journal, 2018, 109, pp.317-325. 10.1016/j.eurpolymj.2018.09.055 . hal-02058211

\section{HAL Id: hal-02058211 \\ https://hal.univ-lorraine.fr/hal-02058211}

Submitted on 23 Jan 2022

HAL is a multi-disciplinary open access archive for the deposit and dissemination of scientific research documents, whether they are published or not. The documents may come from teaching and research institutions in France or abroad, or from public or private research centers.
L'archive ouverte pluridisciplinaire HAL, est destinée au dépôt et à la diffusion de documents scientifiques de niveau recherche, publiés ou non, émanant des établissements d'enseignement et de recherche français ou étrangers, des laboratoires publics ou privés.

\section{(1) (1) $\$$}

Distributed under a Creative Commons Attribution - NonCommercial - NoDerivatives 44.0 
Multi-reactive surfactant and miniemulsion Atom Transfer Radical Polymerization: an elegant controlled one-step way to obtain dextran-covered nanocapsules

Laura Marcela Forero Ramirez ${ }^{1}$, Jérôme Babin ${ }^{1}$, Marc Schmutz ${ }^{2}$, Alain Durand ${ }^{1}$, Jean-Luc Six ${ }^{1}$, Cécile Nouvel ${ }^{1 * \pm}$

1) Université de Lorraine, CNRS, LCPM, F-54000 Nancy, France

2) Université de Strasbourg-CNRS- Institut Charles Sadron UPR22, Strasbourg, France \pm Current address Université de Lorraine, CNRS, LRGP, F-54000 Nancy, France

*corresponding author

*Correspondence to: cecile.nouvel@univ-lorraine.fr

(Submitted to European Polymer Journal) 


\section{Summary}

A convenient one-step method is developed to prepare potentially biocompatible nanocapsules (NCs) with a biocompatible oily core (Miglyol 810, M810), a poly(methyl methacrylate) (PMMA) shell and a dextran coverage. For that, a multi-reactive dextran derivative containing both hydrophobic phenoxy and ATRP initiator groups is used as inisurf (macroinitiator and stabilizer) in an Activator Generated by Electron Transfer-Atom Transfer Radical Polymerization (AGET-ATRP) miniemulsion process. Such dextran inisurfs are shown to efficiently stabilize the direct miniemulsion of MMA with M810 as co-stabilizer, and to confine the polymerization at the oil/water interface via their multiple initiator sites. Grafted copolymers are produced from the inisurf, whose grafts constitute the inner polymeric shell of NCs and are linked to the dextran coverage. The confinement of such polymerization at interface is found to reduce initiator group efficiency, but also to improve both polymerization kinetics and control in comparison with one molecular model initiator. Increasing M810 content promotes the oily core/PMMA shell phase separation during polymerization and the formation of slightly larger NCs, without affecting polymerization kinetics.

Keywords: Nanoparticle; Polysaccharide; Inisurf; Controlled Radical Polymerization; Reversible-Deactivation Radical Polymerization, Poly(methyl methacrylate); 


\section{Introduction}

Nanomedicine research is currently an area of intense scientific interest due to a wide variety of potential biomedical applications, particularly in cancer therapies[1, 2]. Indeed the development of new drug nanocarriers proposes a solution to the delivery of poor water soluble or labile drugs, as well as to their controlled and targeted release[3]. Among the various types of nanocarriers, nanocapsules (NCs) are increasingly used[4, 5]. These nano-vesicular systems exhibit a typical core-shell structure constituted of a liquid core containing drugs and surrounded by a shell acting as a protective membrane. They appear as very promising compared to other drug delivery systems because of the versatile character of their inner liquid core (oil or water), their reduced polymer content and their high encapsulation efficiency[4,6]. Many techniques have been developed to synthesize NCs[7-9]. The most frequent methods use either the hard templating against sacrificial solid particles[10, 11] or soft templates such as emulsion droplets, nanoparticles (NPs) or vesicles[4, 12]. However, the tedious procedures required to achieve a well-defined morphology for NCs and the involved laborious treatments both lead to practical limitations.

Most recently, other methods were introduced to overcome previous problems such as Polymerization-Induced Self-Assembly [13-15] or miniemulsion polymerization [16, 17], which has attracted increased attention This technique allows the production of polymeric NCs and the incorporation of drug in a single step with high encapsulation efficiency[18, 19]. In these systems, polymerization takes place inside the monomer droplet, which makes possible the drug encapsulation into the NCs. In addition, one of the major interests of such miniemulsion polymerization is its ability to produce nano-objects whose size distribution is quite similar to the one of the initial monomer droplets[20]. For that, coalescence can be reduced by the addition of a stabilizer during the polymerization[18], while the addition of a compound with ultra-low solubility in the continuous phase (called co-stabilizer or hydrophobic agent) 
avoids monomer diffusion from small to large droplets (Ostwald ripening). In the case of oily core NCs, oil is added in the monomer phase and can also acts as co-stabilizer. NCs shell is mostly formed during the polymerization stage by phase segregation between the growing polymeric shell and the liquid core. Nevertheless, the use of phase segregation is a very delicate process, especially when the control of NC morphology is aimed[21, 22].

Another method consists to confine the polymerization at the interface using a reactive surfactant. The latter contains reactive groups and consequently acts both as stabilizer and reactant during the polymerization. Such reactive functionalities can be either initiator or transfer agent, resulting in reactive stabilizers called inisurfs or transurfs, respectively. These compounds, located at the interface during the polymerization, ensure also the hydrophilic coverage of the final NCs, which is very important to ensure their colloidal stability in biological medium[23] and to reduce their recognition by the immune system[5].

Moreover, the control of the shell thickness of NCs is essential when aiming drug delivery system applications, especially for appropriate tuning of the drug release kinetics[24]. To reach this shell control within a miniemulsion process, the most attractive technique is to combine the use of an inisurf or a transurf with a Reversible-Deactivation Radical Polymerization (RDRP, former called Controlled Radical Polymerization)[22, 25, 26]. In this prospect and during the polymerization, polymer chains grow from the reactive stabilizer at the miniemulsion droplet interface, producing copolymers at this interface. Such copolymers will constitute the NCs with a coverage made of the initial reactive surfactant part and a shell produced by the obtained polymeric one. With the molecular weight control brought by RDRP, this method offers flexibility with regard to NCs morphology (shell thickness, coverage, surface functionalization ...). Indeed, it has been shown to be quite efficient for the production of NCs with several mono-reactive surfactants, either PEO-based inisurfs,[27-29] polymethacrylates-based transurfs[30-34] or poly(maleic anhydride)-based transurfs,[22, 35, 36] when using Atom 
Transfer Radical Polymerization (ATRP) and Reversible Addition-Fragmentation ChainTransfer polymerization (RAFT polymerization), respectively.

In this context, no multi-reactive inisurfs or transurfs have been previously investigated to produce NCs by RDRP in miniemulsion. To this goal, multi-reactive inisurfs will be derivated from dextran (a biocompatible, neutral and hydrophilic polysaccharide[2]) by the introduction of hydrophobic side groups (conferring surfactant properties) as well as ATRP initiator sites (Scheme 1). Such derivatives will stabilize the miniemulsion to in fine produce dextran-covered NCs for drug delivery. We have already shown that potentially biocompatible NPs can be obtained via an ATRP in miniemulsion using no-reactive dextran derivatives as stabilizer, and methyl methacrylate (MMA) and Miglyol 810 (M810 used here as co-stabilizer, is a mediumchain triglyceride widely used in pharmaceutical formulations[37]), as organic compounds [38]. Nevertheless, inisurfs have never been employed in such a system. The present study explores in depth the control of the AGET-ATRP of MMA in miniemulsion using dextranbased inisurfs as stabilizers and M810 both as oil and co-stabilizer. Thanks to the multifunctionalilty of such inisurfs, grafted copolymers (Dex-g-PMMA) will be synthesized at the interface (Scheme 1) to constitute the NCs hydrophilic dextran coverage covalently linked to the polymeric shell[39].

We also aim to demonstrate the versatility of this method to produce NCs with various loading capacities by the investigation of the influence of M810 content on the miniemulsion stability, on the polymerization control and kinetics, on the NCs morphology as well as on the relative amount of dextran derivative in the final objects. 


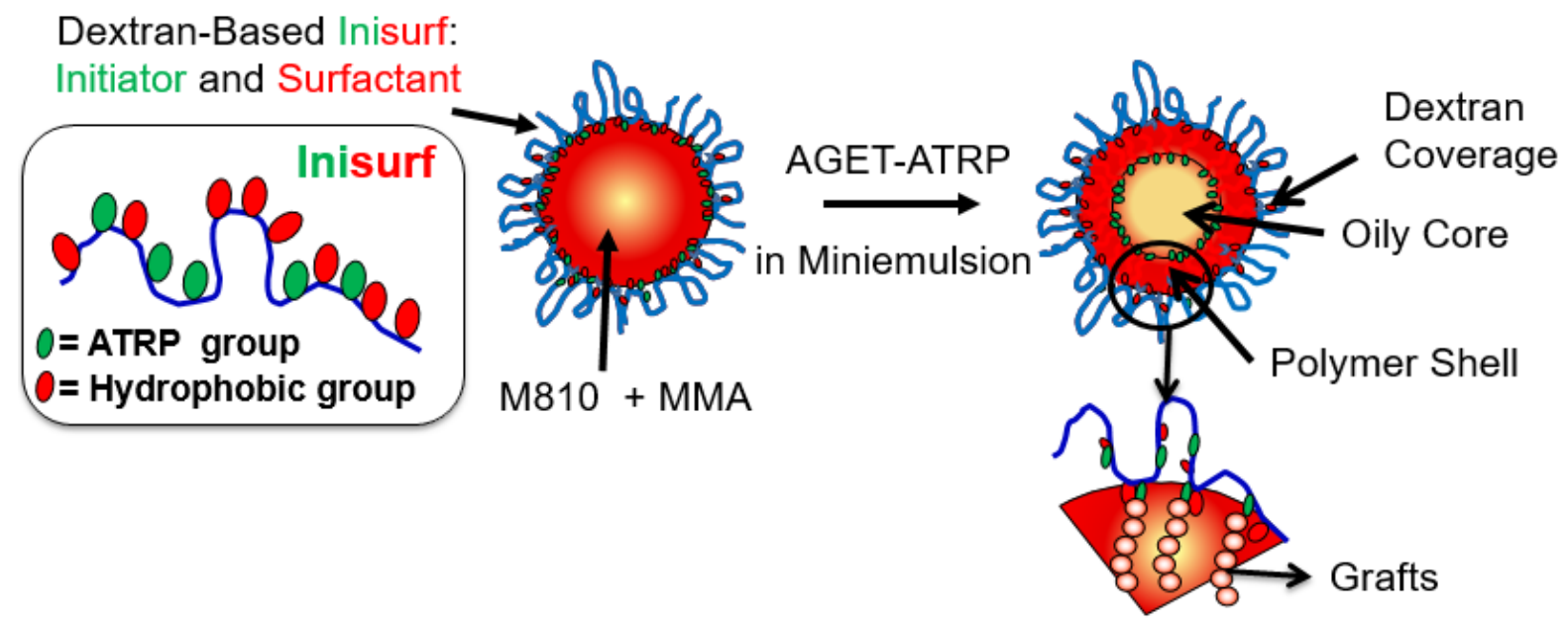

Scheme 1. Synthesis of dextran-covered oily-core NCs by an AGET-ATRP of MMA in miniemulsion and using a multi-reactive dextran-based inisurf. Zoom on one droplet during polymerization.

\section{Experimental}

\subsection{Materials and Methods}

Dextran T40 $\left(\bar{M}_{n}=34,800 \mathrm{~g} \mathrm{~mol}^{-1}\right.$ and $Đ=1.2$; values determined by Size Exclusion Chromatography coupled to a Multi-Angle Light Scattering detector (SEC-MALLS) in water $\left.\left(0.1 \mathrm{M} \mathrm{NaNO}_{3}\right)\right)$ was purchased from Aldrich. Dextran was dried under reduced pressure at $100^{\circ} \mathrm{C}$ overnight for anthrone titration. Ethyl 2-bromoisobutyrate (EiBr), copper dibromide $\left(\mathrm{Cu}^{\mathrm{II}} \mathrm{Br}_{2}\right)$, ascorbic acid (AA) and ethylenediaminetetraacetic acid (EDTA) were purchased from Aldrich and used without further purification. Methyl Methacrylate (MMA, 99\% Aldrich) was vacuum distilled on $\mathrm{CaH}_{2}$. N, N-bis(2-pyridylmethyl)octadecylamine (BPMODA) was prepared using literature procedures[40] with slight modifications. Lipophilic Miglyol810 $\left(\mathrm{M} 810, \mathrm{~d}=0.94 \mathrm{~g} / \mathrm{cm}^{3}\right.$, viscosity $=28 \mathrm{mPa} . \mathrm{s}$ at $20^{\circ} \mathrm{C}$, water content: $0.02 \mathrm{wt} \%$ ) was a gift from Cremer Oleo Division and used as co-stabilizer without further purification. Phenoxy-modified dextrans called DexP $\tau$ were synthesized as previously described[38, 41]. Then DexP $\tau$ were further modified based on our previous work[42, 43] to introduce bromoester groups and thus to produce $\operatorname{DexP} \tau \operatorname{Br} \gamma[39] . \tau$ and $\gamma$ are the numbers of $\mathrm{P}$ and $\mathrm{Br}$ groups per 100 glucopyranosic 
units, respectively, and were determined by ${ }^{1} \mathrm{H}$ NMR in DMSO- $d_{6}$. DexP $\tau$ and DexP $\tau$ Br $\gamma$ were both used as stabilizers in the emulsion polymerization.

2.2. Emulsion preparation and AGET ATRP of MMA in miniemulsion

Typical experimental conditions were as follows: $[\mathrm{MMA}]_{0} /[\mathrm{Br}]_{0} /\left[\mathrm{Cu}^{\mathrm{II}} \mathrm{Br}_{2} / \mathrm{BPMODA}\right]_{0} /[\mathrm{AA}]_{0}=\mathrm{X} / 1 / 0.5 / 0.2$ (molar ratio), $[\mathrm{DexP} \tau \text { or } \operatorname{DexP} \tau \mathrm{Br} \gamma]_{0}=$ $10 \mathrm{~g} / \mathrm{L}, \operatorname{DexP} \tau$ (or DexP $\tau$ Br $\gamma$ ) / organic phase (MMA+M810) varying from 3.1 to $21.8 \mathrm{wt} \%$ and M810/MMA from 5 to 50 vol\%. For each experiment, MMA amount was kept constant to 1.1 $\mathrm{mL}, \mathrm{M} 810$ volume was adjusted in agreement with the M810/MMA ratio and 1 equivalent of BPMODA per $\mathrm{Cu}^{\mathrm{II}} \mathrm{Br}_{2}$ was used. For example, in case of $\mathrm{X}=221$, (DexP $\tau$ or $\operatorname{DexP} \tau \mathrm{Br} \gamma) /(\mathrm{MMA}+\mathrm{M} 810)=14 \mathrm{wt} \%$ and M810/MMA equal to 5 vol\%, $150 \mathrm{mg}$ of dextran derivative (DexP $\tau$ or $\operatorname{DexP} \tau \mathrm{Br} \gamma$ ) were dissolved in $15 \mathrm{~mL}$ of MilliQ water. The organic phase was typically composed of $1.1 \mathrm{~mL}(10.3 \mathrm{mmol})$ of MMA, $10.5 \mathrm{mg}(0.023 \mathrm{mmol})$ of BPMODA, $5.2 \mathrm{mg}(0.023 \mathrm{mmol})$ of $\mathrm{CuBr}_{2}$ and $55 \mu \mathrm{L}$ of M810(co-stabilizer). This phase was heated $\left(60^{\circ} \mathrm{C}\right)$ under stirring for 1 hour and homogenized in an ultrasonic bath during 15 min to improve catalyst solubilization. For experiment with $\operatorname{DexP} \tau$ (case of model studies), $7 \mu \mathrm{L}$ (0.047 mmol) of $\mathrm{EiBr}(\mathrm{MMA} / \mathrm{Br}=221)$ was added into the organic phase, while no $\mathrm{EiBr}$ was added in case of polymerization from $\mathrm{DexP} \tau \mathrm{Br} \gamma$ or for stability experiments. After stirring for 1 hour at $0-5^{\circ} \mathrm{C}$, the formed emulsion was quickly sonicated in an ice bath during 2 minutes (51\% amplitude (power $46 \mathrm{~W}$ ), pulsed mode) using a Vibra cell ${ }^{\text {TM }} 75043$ (Bioblock Scientific, $750 \mathrm{~W}$ max power). The resulting miniemulsion was transferred to a round-bottom flask covered with a septum and purged with nitrogen during $40 \mathrm{~min}$ at $10^{\circ} \mathrm{C}$. The reactor was then immersed in a thermostated oil bath at the reaction temperature $\left(60^{\circ} \mathrm{C}\right)$. Polymerization was started by dropwise addition of $0.009 \mathrm{mmol}$ of AA ( $164 \mu \mathrm{L}$ of $10 \mathrm{~g} / \mathrm{L}$ water solution) during 10 minutes. To estimate the conversion yield and the evolutions of both particle size and molar masses, samples have been taken at different times throughout the reaction (approximately over 2 
hours). Monomer conversion (x) was determined by ${ }^{1} \mathrm{H}$ NMR in DMSO- $d_{6}$ according to Equation 1 by comparison of $\left(\mathrm{A}_{\mathrm{CH}} / \mathrm{A}_{\mathrm{p}}\right)$ ratio at time $t$ with the one at initial time. $\mathrm{A}_{\mathrm{P}}$ corresponded to the area of aromatic protons (between 6.8 and 7.5ppm) and $\mathrm{A}_{\mathrm{CH}}$ (between 5.5 and $6.2 \mathrm{ppm}$ ) to the two methylene protons of the monomer.

$$
\mathbf{x}=\mathbf{1}-\frac{[M]_{t}}{[M]_{\mathbf{o}}}=\mathbf{1}-\frac{\left(\mathbf{A}_{\mathbf{C H}} / \mathbf{A}_{\mathbf{p}}\right)_{t}}{\left(\mathbf{A}_{\mathbf{C H}} / \mathbf{A}_{\mathbf{p}}\right)_{\mathbf{o}}}
$$

One part of the withdrawn suspension was then kept apart for size measurements, when the other part was centrifuged. Recovered NCs were dried under vacuum to remove unreacted MMA and then dissolved in THF for SEC-MALLS analysis, whereas the floating was analyzed by anthrone titration [39] to estimate the quantity of $\mathrm{DexP} \tau$ (or $\operatorname{DexP} \tau \mathrm{Br} \gamma$ ) remaining in aqueous solution. By difference with the initially introduced amount, one can estimate the dextran derivative amount at NCs surface.

\subsection{Cleavage of the PMMA grafts from dextran backbone}

To study the PMMA grafts, $50 \mathrm{mg}$ of dried NCs containing DexP-g-PMMA at coverage/shell interface was completely degraded using $6 \mathrm{~mL}$ of THF/(1M KOH-MeOH) (2/1 $\mathrm{v} / \mathrm{v}$ ) under stirring at room temperature for $72 \mathrm{~h}$. The recovered mixture was then neutralized with $1 \mathrm{M} \mathrm{HCl}$. After evaporation of THF and methanol, PMMA chains were solubilized in toluene and the solution was filtered in order to remove $\mathrm{KCl}$. PMMA was recovered by precipitation with petroleum ether, centrifugation and was then dried overnight under vacuum. The recovered PMMA were analyzed by ${ }^{1} \mathrm{H}$ NMR in DMSO- $d_{6}$ to prove the absence of the dextran backbone. The molar masses of PMMA chains and their distribution were also characterized by SEC-MALLS in THF. The absence of PMMA chain degradation and the stability of the methyl ester of each monomer unit have already been reported under these hard basic conditions $[42,44,45]$. 


\subsection{Purification of NCs to extract copper salt}

$20 \mathrm{mg}$ of dried NCs were dispersed in $0.5 \mathrm{~mL}$ of MilliQ water, then 5 equivalents of EDTA per mol of copper in the system were added. The suspension was left under stirring 24 hours. NCs were then recuperated by centrifugation, washed and finally dried under vacuum. $15 \mathrm{mg}$ of purified NCs were dispersed in $100 \mathrm{~mL}$ of water and $1.5 \mathrm{~mL}$ of nitric acid (99\%) was then added. The copper concentrations, before and after treatment, were measured using a Spectrometer ICAP 6000 SERIES with the help of a standard curve previously established with known copper concentrations. This Inductively Coupled Plasma-Optical Emission Spectrometer is able to measure metal concentrations in the range $0.5-10 \mathrm{ppm}$ in aqueous solutions.

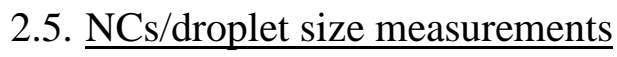

Droplet and NCs sizes were measured by dynamic light scattering at low concentration using an HPPS instrument from Malvern. Although this apparatus was able to measure relatively concentrated samples, we operated with dilute samples by diluting $200 \mu \mathrm{L}$ of emulsions or suspensions in $2 \mathrm{~mL}$ of $10^{-3} \mathrm{M} \mathrm{NaCl}$ solution. Measurements were repeated three times and average values were given. The deviation remained below $5 \mathrm{~nm}$ in all cases and PDI values were close to 0.1 .

\subsection{Characterizations}

${ }^{1} \mathrm{H}$ NMR spectra were recorded on a Bruker Avance 300 apparatus $\left(300.13 \mathrm{MHz}, 25^{\circ} \mathrm{C}\right)$ in DMSO- $d_{6}$.

SEC-MALLS analyses of PMMA chains were performed in THF at $40^{\circ} \mathrm{C}$ using a Waters 515 HPLC pump equipped with a degazer, a temperature controller and three PLgel $5 \mu \mathrm{m}$ columns (100 ̊, $1000 \AA$ and $10000 \AA$, columns (300 x 7.5 mm, P/N 1100-6350, Polymer laboratories)) at elution rate $1 \mathrm{~mL} / \mathrm{min}$. Two detectors were used online: a MALLS detector (Mini Dawn Treos Wyatt -Wyatt Technology Corporation) and a differential refractometry (OPTI Lab rex 
Wyatt). Solutions $(10 \mathrm{mg} / \mathrm{mL})$ were prepared by dissolution in the eluent and were left under vigorous stirring for $24 \mathrm{~h}$. Filtration of these solutions was carried out right before injection. Refractive index increment $(\mathrm{dn} / \mathrm{dc})$ of $0.087 \mathrm{~mL} \cdot \mathrm{g}^{-1}$ was used for PMMA in THF.

Modulated Differential Scanning Calorimetry (MDSC) experiments were conducted on a DSC Model Q2000 (TA Instruments, USA). Accurately weighed samples of PMMA/M810 blends(5 - $10 \mathrm{mg}$, from 2 to $50 \mathrm{wt} \%$ of M810) were sealed in an aluminium pan and then subjected to three heating/cooling cycles in the temperature range of $-70{ }^{\circ} \mathrm{C}-250{ }^{\circ} \mathrm{C}$ with a controlled ramp rate of $5^{\circ} \mathrm{C} / \mathrm{min}$ (modulation amplitude $\pm 1^{\circ}$, duration $40 \mathrm{~s}$ ). The sample cell was constantly purged with $50 \mathrm{~mL} / \mathrm{min}$ of dry nitrogen. First MDSC cycle was used to remove all thermal history from the sample. Analysis of the data was performed using Universal ${ }^{\circledR}$ Analysis 2000 (version 4.5A) software. Glass transition temperature ( $\left.\mathrm{T}_{\mathrm{g}}\right)$ of PMMA and eventually melting point $\left(\mathrm{T}_{\mathrm{m}}\right)$ of M810 were identified in the second scan.

NCs morphology was observed by cryo-Transmission Electron Microscopy (cryo-TEM). The vitrification of the samples was carried out in a homemade vitrification system. The chamber was held at $22{ }^{\circ} \mathrm{C}$ and the relative humidity at $80 \%$. A $5 \mu \mathrm{L}$ drop of the sample was deposited onto a lacey carbon film covered grid (Ted Pella) rendered hydrophilic using an ELMO glow discharge unit (Cordouan Technologies). The grid is automatically blotted to form a thin film which is plunged in liquid ethane hold at $-190{ }^{\circ} \mathrm{C}$ by liquid nitrogen. In that way a vitrified film is obtained in which the native structure of the NCs is preserved. The grid was mounted onto a cryo holder (Gatan 626) and observed under low dose conditions in a Tecnai G2 microscope (FEI) at $200 \mathrm{kV}$. Images were acquired using an Eagle slow scan CCD camera (FEI). For these analysis, washed NCs suspension ( 8 wt.\% solid content) was diluted by a factor of 200.

\section{Results and discussion}

Dextran-based inisurfs were produced according to previous paper [39]. Such inisurfs, called DexP $\tau \mathrm{Br} \gamma$, included both several hydrophobic phenoxy groups $(\mathrm{P})$ and some ATRP 
initiator groups (Br) along their dextran chain (Figure 1). Modification degrees $\tau$ and $\gamma$ are the numbers of $\mathrm{P}$ and $\mathrm{Br}$ groups per 100 glucopyranosic units, respectively. In our previous researches, $\operatorname{DexP} \tau \mathrm{Br} \gamma$ inisurfs with $\tau$ equal to or higher than 15 were shown to act both as stabilizer and macroinitiator in minimemulsion of n-butyl acrylate by Activator Generated by Electron Transfer (AGET)-ATRP [39] to produce dextran-covered NPs. Our objectives here were to extend the use of such a multi-reactive inisurf system by using MMA/M810 mixture as organic phase. Besides, we investigated how to increase the amount of M810 in order to i) produce NCs with PMMA shell and M810 oil core; ii) achieve NCs with high oily core content.

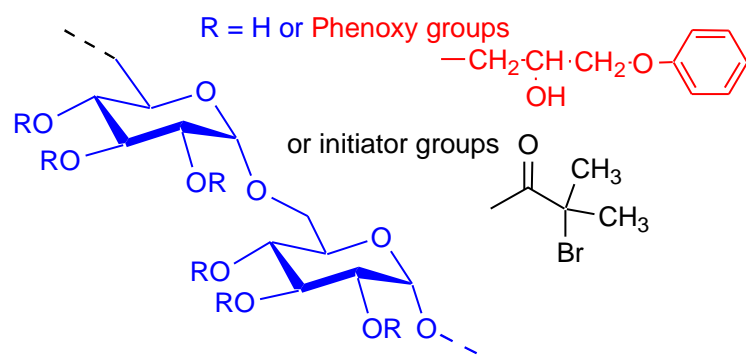

Figure 1. Structure of DexP $\tau B r \gamma$ inisurf

\subsection{Influence of stabilizer and M810 amount on droplets diameter}

At first, oil-in-water nanoemulsions were prepared with an organic phase composed of MMA and various amounts of M810, without addition of initiator into the organic phase. By this way, we investigated both the efficiency of dextran-based stabilizer for producing nanoemulsions and the influence of experimental conditions on the initial droplets size. For those assays, $\operatorname{DexP} \tau \mathrm{Br} \gamma$ inisurf was replaced by $\operatorname{DexP} \tau$ as no-reactive stabilizer, since it has been previously shown that the surfactant abilities of both derivatives were quite similar when $\gamma$ remained below 11[39]. We also decided to fix the amount of water and the DexP $\tau$ concentration but to vary the volumes of MMA and of M810.

Both types of $\operatorname{DexP} \tau\left(\operatorname{DexP}_{16}\right.$ and $\left.\operatorname{DexP}_{20}\right)$ led to very similar results (Figure 2$)$. The substitution degrees of $\operatorname{DexP} \tau$ were sufficient to make them efficient stabilizers for oil-in water 
emulsions. In addition, for a given amount of M810 in oil phase (5, 25 or $50 \mathrm{vol} \%)$, it appeared that plotting the droplet diameter as function of the DexP $\tau$ /organic phase weight ratio allowed one to gather all the experiments onto a single curve (Figure 2). As in our previous studies[38, 39], the DexP $\tau$ /organic phase weight ratio appeared as the relevant parameter to fix the nanodroplet diameters in all cases. For example, when 5 vol\% of M810 was introduced in the organic phase, nanodroplets diameter decreased with increasing DexP $\tau$ /organic phase ratio up to a critical value (about $10 \mathrm{wt} \%$ ) as the $\operatorname{DexP} \tau$ accumulated at the interface increased the interfacial area. It levelled off above this critical weight ratio value once the interface was saturated and a minimum size of droplets was achieved, in accordance to the energy applied to the system [46]. For the higher amounts of M810 in the organic phase (25 and 50 vol\%), all the experiments fit approximately onto the same curve but the droplet sizes were slightly higher compared to those of $5 \mathrm{vol}$. \%. This may be attributed to the lower water interfacial tension for MMA compared to M810 $\left(14.3 \mathrm{mN} / \mathrm{m}\right.$ at $22.7^{\circ} \mathrm{C}[47]$ versus $22.5 \mathrm{mN} / \mathrm{m}$ at $20^{\circ} \mathrm{C}[48]$, respectively). It appeared only for the highest amount of MMA as previously established for another system [49].

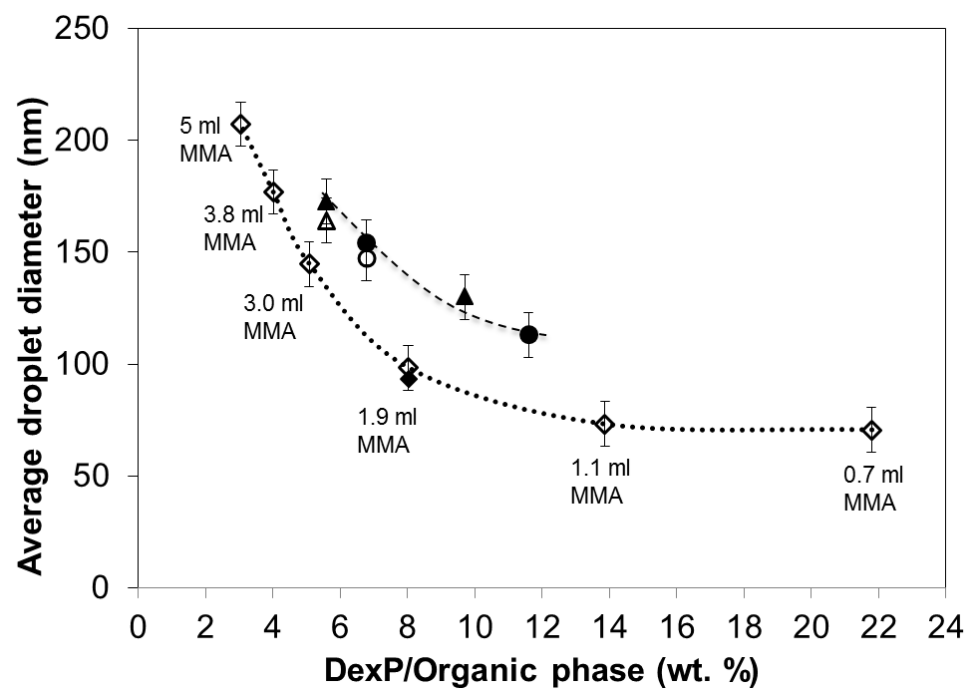

Figure 2. Average droplet diameter versus DexP $\tau$ /organic phase weight ratio. Emulsions were prepared by the dispersion of organic phase (MMA + M810) into an aqueous solution of DexP $\mathrm{P}_{20}$ (full symbols) or DexP 16 (open symbols). M810 amount compared to MMA: ( 5 vol.\% [38], $(\bullet) 25$ vol. $\%$ or $(\boldsymbol{\Delta}) 50$ vol.\%. 


\subsection{Miniemulsion polymerization}

As already studied in our previous works[38, 39], activators generated by AGET system were employed to overcome the restrictions for the use of $\mathrm{Cu}^{\mathrm{I}} \mathrm{Br}$ in dispersed medium (sensible to water and to the air). For that, more stable $\mathrm{Cu}^{\mathrm{II}} \mathrm{Br}_{2}$ was employed and in situ reduced by the addition of AA as reducing agent during polymerization. Experimental conditions were the same as those previously optimized [38], i.e. reaction was carried out at $60^{\circ} \mathrm{C}$ with a $[\mathrm{Br}]_{0} /\left[\mathrm{Cu}^{\mathrm{II}} \mathrm{Br}_{2} / \mathrm{BPMODA}\right]_{0} /[\mathrm{AA}]_{0}$ molar ratio equal to $1 / 0.5 / 0.2$ and stabilizer concentration equal to $10 \mathrm{~g} / \mathrm{L}$. Here, our aims were first to compare our model results using DexP $\tau$ as stabilizer and ethyl 2-bromoisobutyrate (EiBr) as model initiator with the use of $\mathrm{DexP} \tau \mathrm{Br} \gamma$ as inisurf. We have compared two inisurfs (DexP ${ }_{18} \mathrm{Br}_{2.3}$ and $\left.\operatorname{Dex}_{20} \mathrm{Br}_{6.6}\right)$ as well as investigated the effect of the amount of M810 co-stabilizer inside the initial organic phase, from 5 to 50 vol\% compared to MMA (Table 1).

Table 1. AGET-ATRP miniemulsion polymerization of MMA at $60^{\circ} \mathrm{C}$ using DexP $\tau \mathrm{Br} \gamma$ as inisurf (or DexP20 as stabilizer) with $[\mathrm{DexP} \tau \mathrm{Br} \gamma \quad$ (or $\operatorname{DexP} \tau)]=10 \mathrm{~g} / \mathrm{L}$, $[\mathrm{Br}]_{0} /\left[\mathrm{CuIIBr}_{2} / \mathrm{BPMODA}\right]_{0} /[\mathrm{AA}]_{0}=1 / 0.5 / 0.2$ and $1.1 \mathrm{~mL}$ of MMA.

\begin{tabular}{|c|c|c|c|c|c|c|c|c|c|}
\hline \multirow[t]{2}{*}{ Run } & \multirow{2}{*}{$\begin{array}{l}\operatorname{DexP} \tau \mathrm{Br} \gamma \\
\text { (or DexP } \tau \text { ) } \\
\text { /organic } \\
\text { phase } \\
\text { (wt. \%) }\end{array}$} & \multirow{2}{*}{$\begin{array}{l}\text { M810/MMA } \\
\text { Ratio } \\
(\text { vol. \%) }\end{array}$} & \multirow{2}{*}{$\begin{array}{l}\text { Inisurf or } \\
\text { Stabilizer }\end{array}$} & \multirow{2}{*}{$\begin{array}{l}\mathrm{DexP} \tau \mathrm{Br} \gamma \\
\text { (or } \operatorname{DexP} \tau) \\
\text { adsorbed }(\%) \\
\text { (a) }\end{array}$} & \multirow[t]{2}{*}[\mathrm{MMA}]{$_{0} /[\mathrm{Br}]_{0}=\mathrm{X}^{(\mathrm{b})}$} & \multicolumn{3}{|c|}{ Nano-objects diameter $(\mathrm{nm})^{(\mathrm{c})}$} & \multirow{2}{*}{$\begin{array}{l}\text { wt. } \% \\
\text { of } \\
\mathrm{NCs}^{(\mathrm{d})}\end{array}$} \\
\hline & & & & & & $\begin{array}{l}\text { After } \\
\text { degassing } \\
\left(\mathrm{t}_{0}\right)\end{array}$ & $\begin{array}{l}\text { After } \\
10 \mathrm{~min} \\
\left(\mathrm{t}_{1}\right)\end{array}$ & Final & \\
\hline 0 & 14 & 5 & $\operatorname{DexP}_{20}$ & 71 & 221 & 185 & 111 & 131 & 7.0 \\
\hline 1 & 14 & 5 & $\operatorname{DexP}_{18} \mathrm{Br}_{2,3}$ & 83 & 690 & 200 & 101 & 111 & 7.4 \\
\hline 2 & 14 & 5 & $\operatorname{DexP}_{20} \mathrm{Br}_{6,6}$ & 95 & 221 & 269 & 91 & 100 & 7.5 \\
\hline 3 & 12 & 25 & $\operatorname{DexP}_{20} \mathrm{Br}_{6,6}$ & 98 & 214 & 129 & 113 & 125 & 8.8 \\
\hline 4 & 10 & 50 & $\operatorname{DexP}_{20} \mathrm{Br}_{6,6}$ & 97 & 216 & 138 & 130 & 131 & 10.2 \\
\hline
\end{tabular}

${ }^{a}$ Relative amount (molar \%) in NCs obtained after polymerization. Expressed as function of the initially introduced $\operatorname{DexP} \tau \mathrm{Br} \gamma$ (or DexP ${ }_{20}$ ) and measured by UV after reaction with anthrone (see experimental part).

${ }^{b}$ Initial molar ratio in the organic phase. In all cases, except for run 0 , it was estimated with the real amount of $\operatorname{DexP} \tau \mathrm{Br} \gamma$ at the interface evaluated in (a) and supposing all the bromoester groups are accessible for polymerization.

${ }^{c}$ Average nano-objects diameter measured by DLS (see experimental). PDI below 0.1.

${ }^{\mathrm{d}}$ Estimated in dispersion on $100 \%$ conversion

\subsubsection{Relative amount of dextran derivatives adsorbed at miniemulsion interface}


In each case the amount of dextran derivative (DexP $\tau$ or $\operatorname{DexP} \tau \operatorname{Br} \gamma)$ in the final nanoobjects was determined by an indirect method and expressed as a relative $\%$ of the stabilizer initially introduced. For that the quantity of stabilizer remaining in the aqueous phase after polymerization was evaluated by titration using anthrone method [32].

In case of the inisurf systems, $\operatorname{DexP} \tau \mathrm{Br} \gamma$ was adsorbed at the organic phase/water interface during the initial stage of the polymerization and initiated the polymerization from its own initiator groups located onto its backbone. The generated grafts constituted the final NCs shell. Thus, the DexP $\tau \mathrm{Br} \gamma$ initially adsorbed at the interface became irreversibly anchored in the final nano-objects and both quantities were considered as similar. Then, the initial MMA/Br molar ratio (called $\mathrm{X}$ in Table 1) can be evaluated from the amount of $\operatorname{DexP} \tau \mathrm{Br} \gamma$ adsorbed at the interface, assuming all the bromoester groups are available for polymerization. As shown in Table $1,83 \%$ of the initially introduced $\mathrm{DexP}_{18} \mathrm{Br}_{2.3}$ (run 1) or about $95 \%$ of $\mathrm{DexP}_{20} \mathrm{Br}_{6.6}$ (runs 2-4) were located at the interface. These values were higher than the one obtained for the

model system (run 0, Table 1). That is certainly due to the presence of $\mathrm{Br}$ groups, which should increase the amount of dextran derivative initially adsorbed at the emulsion interface and thus, the one in the final NCs (Table 1, runs 0-4). Having most of the inisurfs initially located at the organic phase/water interface was very convenient to prevent micelle formation in aqueous medium and thus homogeneous nucleation. In addition, the low solubility and the instability of $\mathrm{Cu}(\mathrm{I})$ in water leading to unreactive copper complexes should limit the homogeneous nucleation in our system.

\subsubsection{Inisurf versus Model systems}

At first, polymerization kinetics were compared between model and inisurf systems with 5 vol\% of M810 in the organic phase (Figure 3, runs 0-2 in Table 1). For the lowest MMA/Br molar ratio $(X=221)$, the kinetics semilogarithmic plot was linear up to more than $50 \%$ of conversion for the model system (Table 1-run 0 ) and $80 \%$ of conversion for the inisurf system 
(Table 1-run 2). After those limit conversion the control of the polymerization was partially lost. When comparing model and inisurf systems, polymerization is faster in the last case despite a delay phenomenon. This faster kinetics has previously been observed for polymerization of n-butylacrylate in miniemulsion with hexadecane as stabilizer, and was attributed to an interfacial phenomenon linked either to the higher vicinity of the polar medium or to a segregation effect at nanodroplet interface similarly to the one observed in very small nanodroplets[50, 51]. As MMA volume was maintained constant to $1.1 \mathrm{~mL}$ for all the experiments, $\mathrm{X}$ was then varied with the inisurf, which influenced the number of initiator groups into the medium, resulting in higher $\mathrm{X}$ for run 1, compared to run 2 (Table 1). As expected, higher $\mathrm{X}$ resulted in a slower polymerization rate but still with a linear kinetics semilogarithmic plot at low conversion.

As in our previous studies with model system[38, 39], latexes obtained after polymerization with inisurfs were very stable without any visible phase separation. Depending on the experimental conditions, the solid content in the final dispersion was calculated on the basis of $100 \%$ conversion and varied between about 7 to $10 \mathrm{wt} \%$ (Table 1 ).

Final NCs diameters were slightly lower than those of the initial nano-droplets and very similar to those of nano-objects obtained after $10 \mathrm{~min}$ of polymerization, i. e. after complete addition of AA (Table 1). The PDI below 0.1 ascertain the relative homogeneity of the distribution (data confirmed by granulometry but not shown here). This result proved the ability of M810 as co-stabilizer to enable oil dispersion and also to limit Ostwald ripening. Indeed larger sizes were initially observed for the minemulsion and arose from the imperfect solubility of the initial catalytic system $\left(\mathrm{Cu}^{\mathrm{II}} \mathrm{Br}_{2} / \mathrm{BPMODA}\right)$ in the initial organic phase, i. e. before $\mathrm{AA}$ addition, when 5 vol\% of M810 was added as co-stabilizer[38].Therefore, the presence of $\mathrm{Cu}^{\mathrm{II}} \mathrm{Br}_{2} / \mathrm{BPMODA}$ in the initial organic phase apparently resulted in the formation of larger nanodroplets (average diameter of $150 \mathrm{~nm}$ or $270 \mathrm{~nm}$, Table 1 runs $0-2$ ) compared to the values 
measured for similar emulsion without catalyst during stability studies (about $100 \mathrm{~nm}$, Figure 2), due to the presence of a few catalyst aggregates, which increases the average size measured by DLS. Thus, as already discussed in previous papers with similar catalytic systems [38, 39], after AA addition, the average diameter of nano-objects decreased due to the reduction of $\mathrm{Cu}^{\mathrm{II}} \mathrm{Br}_{2}$ into $\mathrm{Cu} \mathrm{Br}$ helping the catalyst solubilisation and the NCs size remained constant throughout all the process.

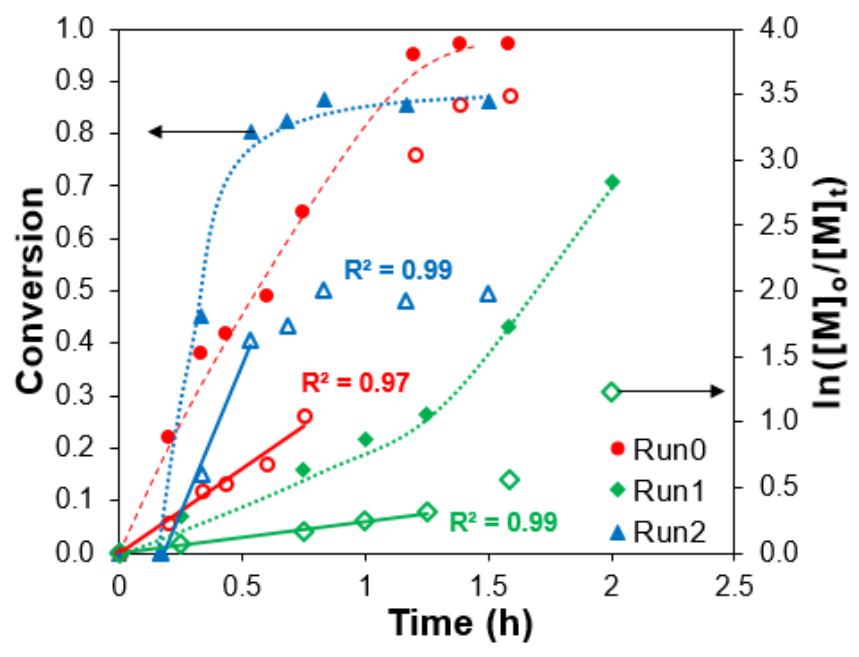

Figure 3. Conversion (full symbols) and $\ln \left([\mathrm{M}]_{0} /[\mathrm{M}]_{\mathrm{t}}\right)$ (open symbols) versus time. AGETATRP of MMA in miniemulsion at $60^{\circ} \mathrm{C}$. [MMA $]_{0} /[\mathrm{Br}]_{0} /\left[\mathrm{Cu}^{\mathrm{II}} \mathrm{Br}_{2} / \mathrm{BPMODA}\right]_{0} /[$ Ascorbic acid $]_{0}=\mathrm{X} / 1 / 0.5 / 0.2, \mathrm{M} 810 / \mathrm{MMA}=5 \mathrm{vol} . \%$. See table 1 for $\mathrm{X}$ and other conditions. [DexP $\tau$ or $\operatorname{DexP} \tau \mathrm{Br} \gamma]=10 \mathrm{~g} / \mathrm{L}$. (•) Run 0, DexP 20 as stabilizer, EiBr as initiator, $\mathrm{X}=221$ ( $\diamond$ ) Run 1, $\operatorname{DexPBr}_{18} \mathrm{Br}_{2.3}, \mathrm{X}=690$, ( $\left.\boldsymbol{\Delta}\right)$ Run 2, DexPBr $20 \mathrm{Br}_{6.6}, \mathrm{X}=221$.

\section{$\underline{\text { 3.2.3 Effect of Miglyol } 810 \text { content }}$}

Our final aim was to prepare PMMA NCs with higher M810 content to evaluate the versatility of the process. For that, several AGET-ATRP were performed with the most efficient inisurf (DexP $\left.\mathrm{P}_{20} \mathrm{~B}_{6.6}\right)$ and with various amounts of $\mathrm{M} 810$, all other parameters being the same.

The first effect of increasing the M810 amount inside the organic phase was observed on the solubility of the ATRP catalytic system $\left(\mathrm{Cu}^{\mathrm{II}} \mathrm{Br}_{2} / \mathrm{BPMODA}\right)$ in the initial organic phase. The hydrophobic character of M810 favored the solubility of the initial catalyst, so the homogeneity of the initial polymerization solutions increased with the M810/MMA volume ratio in the initial organic phase. Complete solubility is almost achieved with 50 vol\% of M810. 
Indeed, the difference between the average nanodroplets diameter (before AA addition) and those of nano-objects after $10 \mathrm{~min}$ of polymerization was progressively reduced when M810/MMA ratio increased from 5 to 50 vol\% (runs 2- 4, Table 1), which again strengthen our hypothesis that this difference arose from imperfect solubility of the catalyst.

The second effect is a slight increase of the nanodroplets/NCs average diameter when increasing M810 content from 5 vol\% to 50 vol\% (runs 2-4, Table1). Indeed, from one experiment to another, the amount of MMA was kept constant to $1.1 \mathrm{~mL}$ and M810 volume was adjusted to attain the expected M810/MMA volume ratio. Consequently, $\operatorname{DexP} \tau \mathrm{Br} \gamma /$ organic phase $\mathrm{wt} \%$ slightly decreased when increasing M810 volume. This was consistent with the idea that it was the driving parameter for nanodroplets/NCs size. Nonetheless, increasing the amount of M810 has no effect on latex stability despite the increase of the final solid content. In addition, all the oil was encapsulated even for the highest proportion of M810.

Concerning kinetics, the conversion evolved very similar whatever the amount of M810 (Figure 4a). Indeed, even the inhibition period was very reproducible. This delay was present for the experiment with the other inisurf (run 1, Table 1 and Figure 3) and has never been observed for the model system (run 0, Table 1 and Figure 3)[38]. Thus, it was doubtful that it came from a degazing problem. Most likely this delay arose from the higher difficulty to initiate the interfacial polymerization from those multi-reactive inisurfs. Contrariwise it was quite surprising that the amount of M810 has no effect on the polymerization rate. Experimental conditions including initial $[\mathrm{MMA}]_{0} /[\mathrm{Br}]_{0}$ ratio $(\mathrm{X})$ being similar for all experiments, it was expected that increasing the hydrophobic content would result in a diminution of reaction rate because of the decrease of medium polarity as usually observed for ATRP[45]. Nevertheless, the presence of high amount of M810 improved catalyst solubility, as highlighted above, and consequently, increased the proportion of effective copper into the droplets, which resulted in 
faster polymerization kinetics. As a consequence, this factor may offset the previously expected polarity effect.

Finally, no effect of the amount of M810 was also observed on the amount of inisurf in the final NCs, and more than $95 \%$ of the initially introduced $\mathrm{DexP}_{20} \mathrm{~B}_{6.6}$ insurf was recovered in the final NCs. As already explained above, the covalent linkage generated during polymerization between the inisurf and PMMA grafts, which constituted the inner shell of the final NCs, prevented its elimination from the NCs, even for the lowest amount of M810.

a)

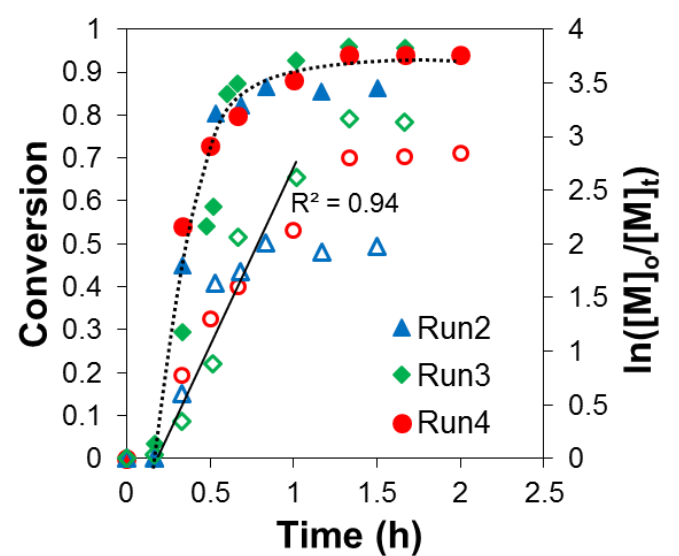

b)

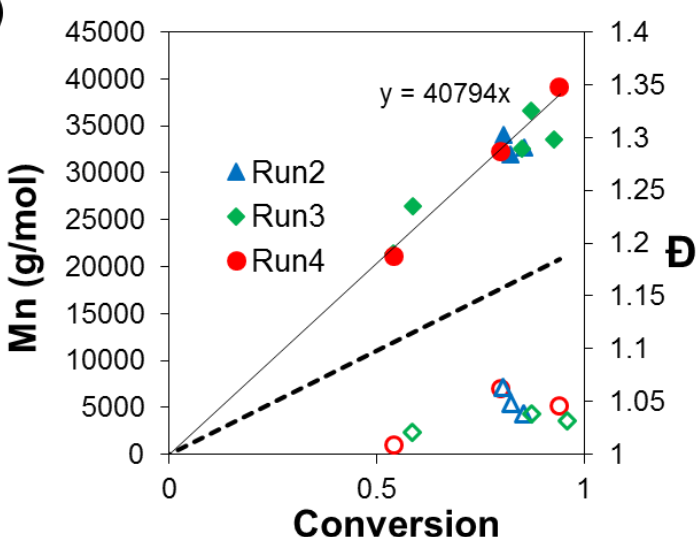

Figure 4. AGET-ATRP of MMA in miniemulsion at $60^{\circ} \mathrm{C}$ using $\mathrm{DexP}_{20} \mathrm{Br}_{6.6}$ as inisurf and increasing amounts of $\mathrm{M} 810$ as co-stabilizer. $\left[\mathrm{DexP}_{20} \mathrm{Br}_{6.6}\right]=10 \mathrm{~g} / \mathrm{L}$. $[\mathrm{MMA}]_{0} /[\mathrm{Br}]_{0} /\left[\mathrm{Cu}^{\mathrm{II}} \mathrm{Br}_{2} / \mathrm{BPMODA}\right]_{0} /[\mathrm{AA}]_{0}=\mathrm{X} / 1 / 0.5 / 0.2$. See Table 1 for $\mathrm{X}$ and other

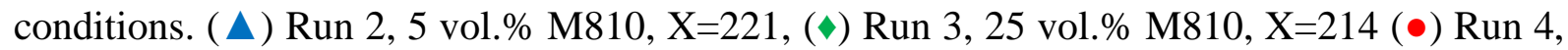
50 vol.\% M810, $\mathrm{X}=216$. a) Conversion (full symbols) and $\ln \left([\mathrm{M}]_{0} /[\mathrm{M}]_{\mathrm{t}}\right.$ ) (open symbols) versus time. b) Evolution of experimental $\bar{M}_{n}$ (full symbols), theoretical $\bar{M}_{n}$ with X=221 (dotted line) and dispersity $\left(\mathrm{Ð}=\bar{M}_{w} / \bar{M}_{n}\right)$ (open symbols) versusconversion.

\subsubsection{Polymerization control and initiator efficiency}

The last point to check concerning the control of this polymerization was the analysis of the grafted copolymers (Dextran-g-PMMA) that were in situ generated by polymerization initiated from the inisurf. As in our previous studies[39], no PMMA homopolymer could be detected or extracted from the final NCs, which was consistent with the absence of any notable transfer reactions. To get further insight, we decided to deliberately cleave the PMMA grafts from the dextran backbone. To that goal, NCs were treated under basic conditions adapted from our previous studies[44, 45]. It had already been shown that the treatment was unharmful for 
PMMA grafts. After total cleavage, PMMA chains were recovered and analyzed by SECMALLS to evaluate their molar masses distribution all along polymerization kinetics (Figure 5). SEC chromatograms at different conversions exhibited almost monomodal distributions, except for the highest conversion (93\%), where one little pic was observed at lower masses. The presence of this small lower masses peak at $93 \%$ of conversion on SEC traces could be attributed to the very beginning of termination reactions by disproportionation, which was consistent with the previous kinetics plot. The experimental average molecular masses $\bar{M}_{n}$ of the grafts evolved linearly with conversion until $90 \%$ of conversion (Figure $4 \mathrm{~b}$ ) without any appearance of noticeable transfer or termination reaction. In addition Dispersity (Đ) remained considerably below 1.1 during the polymerization. All these results proved the control of the polymerization almost until the highest conversions.

Furthermore experimental $\bar{M}_{n}$ are considerably higher than the theoretical ones (calculated with the adjusted value of $\left.\mathrm{X}=[\mathrm{MMA}]_{0} /[\mathrm{Br}]_{0}=221\right)$. The comparison between experimental and theoretical $\bar{M}_{n}$ of PMMA grafts (Figure 4b) allowed us to evaluate an average initiator efficiency for the inisurf $\mathrm{DexP}_{20} \mathrm{Br}_{6.6}$. This efficiency corresponded to the inverse of the slope, i. e. $54 \%$. It meant that only half of the initial bromoester groups of $\operatorname{DexP}_{20} \mathrm{Br}_{6.6}$, which was located at the interface, effectively participated in the chains growth. This value appeared to be the same whatever the M810 content, unlike the high efficiency obtained with EiBr in the model studies at least at the beginning of the polymerization conversion[38]. This lower initiator efficiency with the inisurf system could be attributed to a limited accessibility of some initiator sites not located at the interface with the organic phase, depending on the inisurf conformation, which were not able to initiate polymerization.

Even though the initiator efficiency is reduced by a factor two, the improvement of the control of polymerization was remarkable compared to the model kinetics obtained with EiBr where transfer reactions appeared above $60 \%$ of conversion[38]: polymerization seems to be quite 
controlled until more than $80 \%$ of conversion, which was considerably above the usual limit conversion obtained for those type of systems. Indeed the confinement of the polymerization at the surface of the emulsion nanodroplet and the big spacing between the initiator sites (i. e. growing sites), due to the low number of active ones, certainly contributed to improve the polymerization as already proved for another surface initiated system[52].

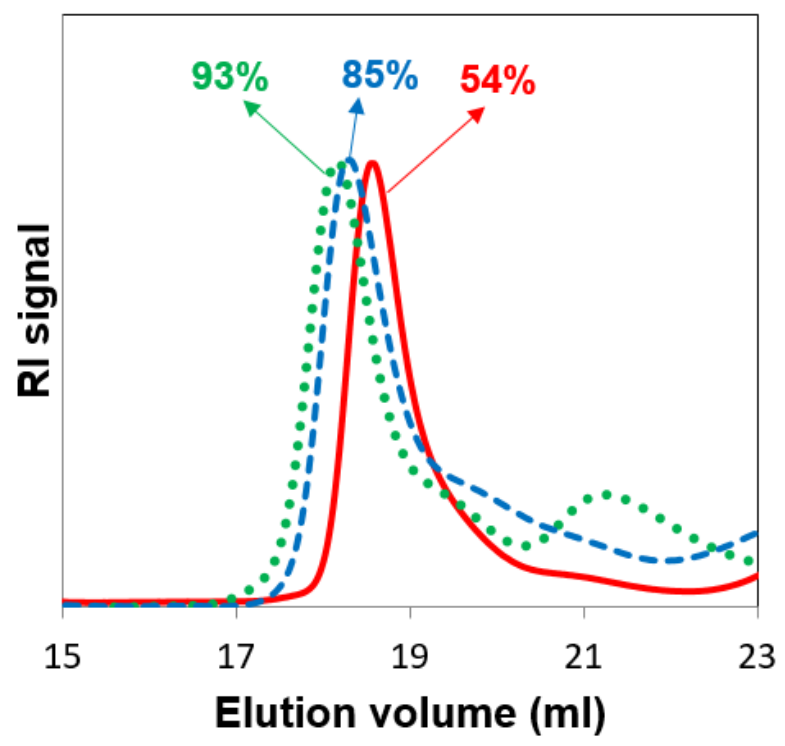

Figure 5. SEC traces (Refractive Index detector) of PMMA grafts versus conversion (indicated on curves). These PMMA grafts were recovered from basic treatment of NCs obtained by AGET-ATRP of MMA in miniemulsion at $60^{\circ} \mathrm{C}$ using $\operatorname{Dex}_{20} \mathrm{Br}_{6.6}$ as stabilizer and $25 \mathrm{vol} . \%$ of M810 as co-stabilizer (Run 3, Table 1).

\subsection{NCs morphology}

\subsubsection{MDSC analysis of PMMA/M810 binary mixtures}

As the expected core-shell structure formation during polymerization is also based on phase segregation between PMMA growing chains (constituting polymeric shell) and M810 (the oily core), we decided to firstly check the PMMA/M810 miscibility. To this goal, the influence of M810 content (2-50 wt.\%) on the glass transition temperature ( $\left.\mathrm{T}_{\mathrm{g}}\right)$ of PMMA/M810 binary mixtures was assessed by MDSC analysis (Figure 6a). Increasing the oil content up to $11 \mathrm{wt} \%$ resulted in a gradual decrease of the $\mathrm{T}_{\mathrm{g}}$ as compared to bulk PMMA (evaluated at $108{ }^{\circ} \mathrm{C}$ ). MDSC thermograms indicated total miscibility of two components in this range since a single 
glass transition endothermic event was encountered. Above $11 \mathrm{wt} \%$, PMMA $\mathrm{T}_{\mathrm{g}}$ no longer decreased and MDSC thermograms showed an additional melting peak. PMMA/M810 mixtures were thus two-phase systems with both: i) a plasticized amorphous phase composed by PMMA and 11 wt. $\%$ of $\mathrm{M} 810\left(\mathrm{Tg}=77.5^{\circ} \mathrm{C}\right)$ and ii) a pure M810 liquid phase exhibiting one melting transition $\left(\mathrm{T}_{\mathrm{m}}=-4^{\circ} \mathrm{C}\right)$. To summarize, PMMA/M810 miscibility was limited to $11 \mathrm{wt} / \%$ of M810 and core-shell nano-structures could be in principle obtained with oil contents above this value (Figure 6b). In addition MDSC thermograms of dried NCs obtained with 25 vol.\% and 50 vol.\% of M810 in the organic phase corroborated these results and confirmed polymer/oil phase separation of these miniemulsion recipes during polymerization.

a)

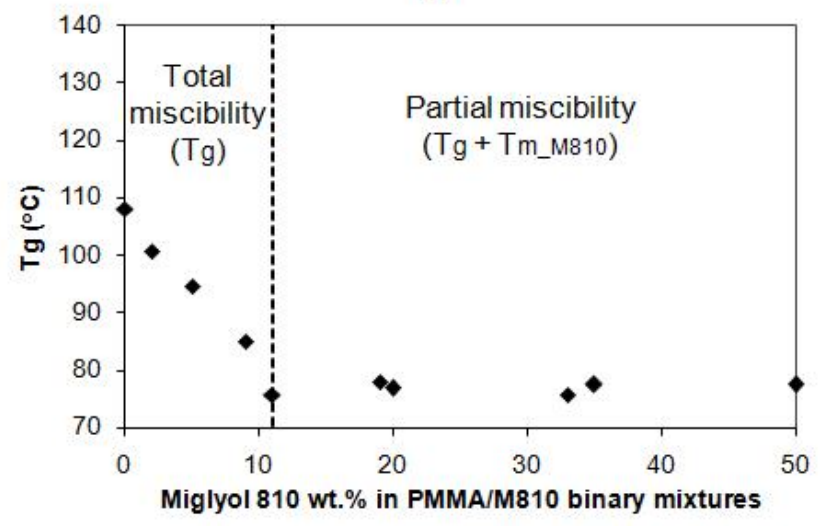

b)

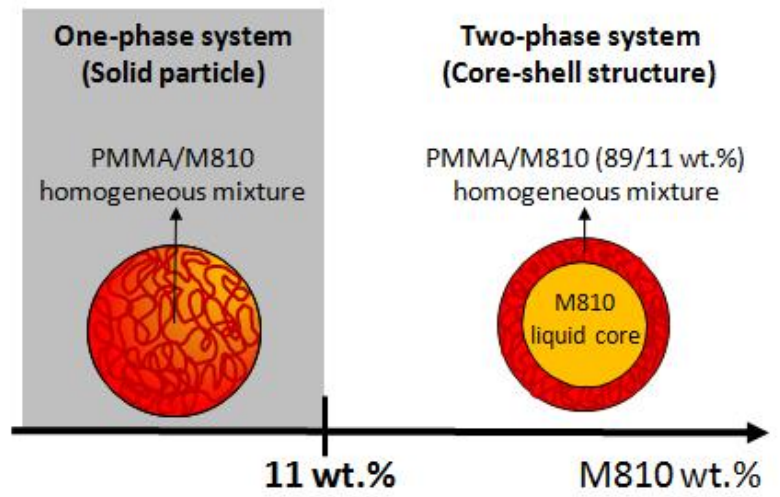

c)

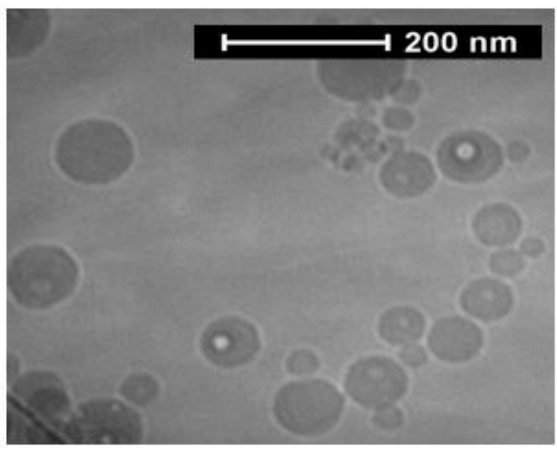

d)

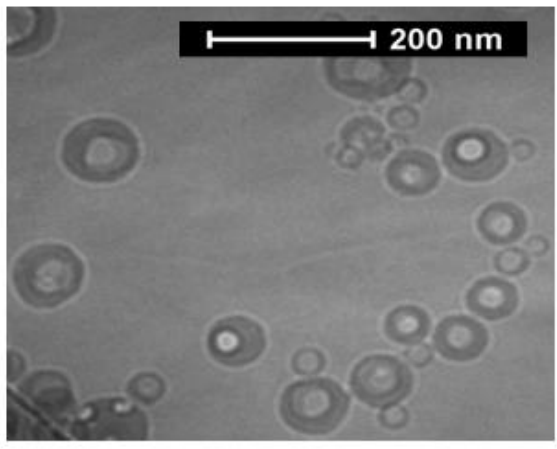

Figure 6. Nano-objects morphological characterizations. a) PMMA Tg in PMMA/M810 binary mixtures as a function of M810 wt.\%, b) Predicted nano-objects morphology and composition at total conversion as a function of M810 wt.\%. c and d) Cryo-TEM micrographs of NCs prepared with $\mathrm{DexP}_{20} \mathrm{Br}_{6.6}$ as stabilizer and 25 vol.\% of M810 in the initial organic phase (run 3 , Table 1) under c) low and d) high beam exposure. 


\section{$\underline{\text { 3.3.2Cryo-TEM observations }}$}

To further prove the oily-core/polymeric shell morphology, final NCs were visualized by cryogenic-Transmission Electron Microscopy (cryo-TEM). Micrographs obtained for run 3 (Table 1) at 93\% of conversion (Figure 6, c and d) show spherical nano-objects, whose sizes were in close agreement with hydrodynamic diameters measured by DLS. Unfortunately, the contrast between plasticized PMMA and M810 phases was not sufficient enough to clearly differentiate NCs structure under normal low-dose beam conditions even at high defocus (Figure 6c). Nevertheless, upon high-intensity exposure to the microscope electron beam, the NCs oily core is more sensitive to irradiation damage making visible the internal liquid cavity (Figure 6d). These observations directly provided an evidence of core-shell structure. Once again, this confirmed the absence of homogeneous and micellar nucleations during polymerization as pure PMMA NPs were not detected at high conversion.

\subsection{NCs purification}

Adverse health effects of residual copper catalyst can reduce the quality and usefulness of nanoobjects prepared by AGET-ATRP, especially in biomedical field. We have already shown that copper catalyst can be efficiently removed from PMMA model NPs (prepared with DexP $\tau / \mathrm{EiBr}$ system) by treatment with EDTA (a strong chelating agent) resulting in about 160 ppm of residual copper in purified NPs[38]. In a parallel study, similar treatment resulted in $15 \mathrm{ppm}$ of residual copper for purified dextran-covered PLA shell NCs obtained by an emulsionevaporation method coupled with an in situ click $\mathrm{Cu}(\mathrm{I})$-catalyzed azide-alkyne cycloaddition (CuAAC) reaction occurring at liquid/liquid interface[9].

To check these results in the case of the present inisurf systems, dextran-covered PMMA shell NCs obtained from DexP ${ }_{20} \mathrm{Br}_{6.6}$ with 5 vol\% of M810 in the organic phase (run 2, Table 1 carried out with $0.5 \mathrm{wt} . \%$ of $\mathrm{Cu}^{\mathrm{II}} \mathrm{Br}_{2}$ related to MMA) were submitted to a similar purification procedure. Extraction with EDTA ( $\sim 5$ equivalents per copper mole) solution for 24 hours 
removed more than $90 \%$ of copper catalyst remaining inside NCs after polymerization (about $20-25 \%$ of the initial copper amount). Copper final amount inside nanocapsules was evaluated to about $100 \mathrm{ppm}$. This corresponds to a concentration of copper in solution below $0.01 \mathrm{mg}$ per ml, with a solid contend of the final NCs solution below $10 \mathrm{wt} \%$. Knowing that halogenated cooper solution containing $0.4 \mathrm{ml}$ of copper per $\mathrm{ml}$ are authorized for intravenous administration [53], residual copper amount could be acceptable for pharmaceutical use, know that the solution can be diluted. In addition, according to the requirements of final application, additional purification steps could be implemented to further reduce the copper content.

\section{Conclusion}

The potential of a new strategy to prepare dextran-covered nano-capsules (NCs) containing biocompatible oil was studied, in the view of controlling their morphology. For that, multifunctional inisurf based on dextran were used as both stabilizer and macroinitiator in miniemulsion AGET-ATRP of methyl methacrylate (MMA) in the presence of Miglyol 810 (M810) as co-stabilizer and oil content, to produce dextran-covered PMMA shell/oily core NCs. The inisurf to organic phase weight ratio appeared as the relevant critical parameter to fix the nanodroplets diameter. Moreover, we have shown that initiator groups were effectively available at oil/water interface for reacting with monomer and thus for initiating the polymerization. A good control over MMA AGET-ATRP was evidenced with inisurf until more than $80 \%$ of conversion in some case, as well as a good stability of the latex for final solid content up to $10 \mathrm{wt} \%$. NCs final size could be controlled by the one of initial emulsion nanodroplets. The inisurf conformation at droplets interface induced some confinement, which seemed both to reduce by half the number of initiator groups effectively available for polymerization but also to improve the polymerization control compared to the model initiator EiBr. Increasing M810 amount up to 50 vol \% compared to MMA in the initial organic phase allowed the preparation of NCs with slightly larger sizes between 100 and $130 \mathrm{~nm}$ without any 
change in initiator group's efficiency or in polymerization kinetics. Furthermore high M810 content is also necessary to encourage the formation of an oily-core/PMMA shell morphology by phase segregation during polymerization.

Under used formulation conditions, most of the initial inisurf amount was adsorbed at NCs surface due to the covalent linking of reactive inisurfs to NCs polymeric shell, preventing the need of additional washings of final objects and improving latex stability. The overall results showed the interest of the present strategy for the preparation of potentially biocompatible dextran-covered nanocarriers. For that, the drug should be loaded after NCs purification, e.g.by supercritical fluid impregnation. Nevertheless other complementary studies would be necessary to determine the real potential of such NCs for drug delivery applications as well as to investigate in depth their morphological characteristics. In the next future, the possibility of extending this strategy from AGET-ATRP to one Reversible Addition-Fragmentation chain Transfer (RAFT) polymerization will also be studied to prevent the use of copper catalyst.

\section{Acknowledgments}

C. Nouvel and L.M Forero Ramirez acknowledge support from ANR JCJC ANR-12-JS080003-01 NANOCAPDEX for funding and PhD Research Fellowship, respectively.

The authors express their highest gratitude to Olivier Fabre for NMR analyzes, to MarieChristine Grassiot for help in SEC measurements, to Frédéric Rozefrom from ENSIC Analytical Center for ICP-OES analyzes, the ICS microscopy platform for the use of the instruments.

\section{Data availability}

There is no Supplementary data associated with this article. 


\section{$\underline{\text { References }}$}

[1] I. Brigger, C. Dubernert, P. Couvreur, Nanoparticulate in cancer therapy and diagnosis., Adv. Drug Delivery Rev. 54 (2002) 631-651.

[2] B. Posocco, E. Dreussi, J. de Santa, G. Toffoli, M. Abrami, F. Musiani, M. Grassi, R. Farra, F. Tonon, G. Grassi, B. Dapas, Polysaccharides for the Delivery of Antitumor Drugs, Materials 8(5) (2015) 2569-2615.

[3] C. Pinto Reis, R.J. Neufeld, A.n.J. Ribeiro, F. Veiga, Nanoencapsulation II. Biomedical applications and current status of peptide and protein nanoparticulate delivery systems, Nanomedicine 2(2) (2006) 53-65.

[4] C.E. Mora-Huertas, H. Fessi, A. Elaissari, Polymer-based nanocapsules for drug delivery, Int. J. Pharm. 385(1-2) (2010) 113-142.

[5] N.T. Huynh, C. Passirani, P. Saulnier, J.P. Benoit, Lipid nanocapsules: A new platform for nanomedicine, Int. J. Pharm. 379(2) (2009) 201-209.

[6] A. Kowalczuk, R. Trzcinska, B. Trzebicka, A.H.E. Müller, A. Dworak, C.B. Tsvetanov, Loading of polymer nanocarriers: Factors, mechanisms and applications, Prog. Polym. Sci. 39(1) (2014) 43-86.

[7] X.W. Lou, L.A. Archer, Z. Yang, Hollow Micro-/Nanostructures: Synthesis and Applications, Adv. Mater. 20(21) (2008) 3987-4019.

[8] J. Cui, M.P. van Koeverden, M. Müllner, K. Kempe, F. Caruso, Emerging methods for the fabrication of polymer capsules, Adv. Colloid Interface Sci. 207 (2014) 14-31.

[9] K. Poltorak, A. Durand, M. Léonard, J.-L. Six, C. Nouvel, Interfacial click chemistry for improving both dextran shell density and stability of biocompatible nanocapsules, Colloids Surf., A 483 (2015) 8-17.

[10] Y. Liu, J. Yang, Z. Zhao, J. Li, R. Zhang, F. Yao, Formation and characterization of natural polysaccharide hollow nanocapsules via template layer-by-layer self-assembly, J. Colloid Interface Sci. 379(1) (2012) 130-140.

[11] S. De Koker, R. Hoogenboom, B.G. De Geest, Polymeric multilayer capsules for drug delivery, Chem. Soc. Rev. 41(7) (2012) 2867-2884.

[12] N. Anton, J.-P. Benoit, P. Saulnier, Design and production of nanoparticles formulated from nano-emulsion templates - A review, J. Controlled Release 128(3) (2008) 185-199.

[13] M.J. Derry, L.A. Fielding, S.P. Armes, Polymerization-induced self-assembly of block copolymer nanoparticles via RAFT non-aqueous dispersion polymerization, Progress in Polymer Science 52 (2016) 1-18.

[14] K. Ferji, P. Venturini, F. Cleymand, C. Chassenieux, J.-L. Six, In situ glyconanostructure formulation via photo-polymerization induced self-assembly, Polymer Chemistry 9(21) (2018) 2868-2872.

[15] J. Lesage de la Haye, X. Zhang, I. Chaduc, F. Brunel, M. Lansalot, F. D'Agosto, The Effect of Hydrophile Topology in RAFT-Mediated Polymerization-Induced Self-Assembly, Angewandte Chemie International Edition 55(11) (2016) 3739-3743.

[16] K. Landfester, A. Musyanovych, V. Mailaender, From Polymeric Particles to Multifunctional Nanocapsules for Biomedical Applications Using the Miniemulsion Process, J. Polym. Sci., Part A: Polym. Chem. 48(3) (2010) 493-515.

[17] A.J.P. van Zyl, R.F.P. Bosch, J.B. McLeary, R.D. Sanderson, B. Klumperman, Synthesis of styrene based liquid-filled polymeric nanocapsules by the use of RAFT-mediated polymerization in miniemulsion, Polymer 46(11) (2005) 3607-3615.

[18] F.R. Steinmacher, N. Bernardy, J.B. Moretto, E.I. Barcelos, P.H.H. Araujo, C. Sayer, Kinetics of MMA and VAc Miniemulsion Polymerizations Using Miglyol and Castor Oil as Hydrophobe and Liquid Core, Chem. Eng. Technol. 33(11) (2010) 1877-1887. 
[19] A.P. Romio, N. Bernardy, E.L. Senna, P.H.H. Araujo, C. Sayer, Polymeric nanocapsules via miniemulsion polymerization using redox initiation, Mater. Sci. Eng., C 29(2) (2009) 514518.

[20] M.B. Casey, E.D. Sudol, M.S. El-Aasser, Evolution of droplet size distribution and composition in miniemulsions, J. Polym. Sci., Part A: Polym. Chem. 52(11) (2014) 15291544.

[21] A.J.P. van Zyl, R.D. Sanderson, D. de Wet-Roos, B. Klumperman, Core/Shell Particles Containing Liquid Cores: Morphology Prediction, Synthesis, and Characterization, Macromolecules 36(23) (2003) 8621-8629.

[22] Y. Luo, H. Gu, Nanoencapsulation via interfacially confined reversible addition fragmentation transfer (RAFT) miniemulsion polymerization, Polymer 48(11) (2007) 32623272.

[23] A. Durand, E. Marie, Macromolecular surfactants for miniemulsion polymerization, Adv. Colloid Interface Sci. 150(2) (2009) 90-105.

[24] J. Siepmann, F. Siepmann, Modeling of diffusion controlled drug delivery, J. Controlled Release 161(2) (2012) 351-362.

[25] M.F. Cunningham, Controlled/living radical polymerization in aqueous dispersed systems, Prog. Polym. Sci. 33(4) (2008) 365-398.

[26] B. Charleux, F. D'Agosto, G. Delaittre, Preparation of Hybrid Latex Particles and CoreShell Particles Through the Use of Controlled Radical Polymerization Techniques in Aqueous Media, in: A.M. van Herk , K. Landfester (Eds.), Hybrid Latex Particles: Preparation with (Mini)emulsion Polymerization, Spinger-Verlag, Berlin, 2010, pp. 125-183.

[27] W. Li, J.A. Yoon, K. Matyjaszewski, Dual-reactive surfactant used for synthesis of functional nanocapsules in miniemulsion, J. Am. Chem. Soc. 132(23) (2010) 7823-7825. [28] W.W. Li, K. Matyjaszewski, K. Albrecht, M. Moller, Reactive Surfactants for Polymeric Nanocapsules via Interfacially Confined Miniemulsion ATRP, Macromolecules 42(21) (2009) 8228-8233.

[29] K. Tian, J. Zeng, X.B. Zhao, L. Liu, X. Jia, P. Liu, Synthesis of multi-functional nanocapsules via interfacial AGET ATRP in miniemulsion for tumor micro-environment responsive drug delivery, Colloids Surf., B 134 (2015) 188-195.

[30] F. Lu, Y. Luo, B. Li, A facile route to synthesize highly uniform nanocapsules: use of amphiphilic poly(acrylic acid)-block-polystyrene RAFT agents to interfacially confine miniemulsion polymerization, Macromol. Rapid Commun. 28 (2007) 868-874.

[31] F. Lu, Y. Luo, B. Li, pH effects on the synthesis of nanocapsules via interfacial miniemulsion polymerization mediated by amphiphilic RAFT agent with the R group of poly(methyl acrylic acid-ran-styrene), Ind. Eng. Chem. Res. 49 (2010) 2206-2212. [32] H. Chen, Y.W. Luo, Facile Synthesis of Nanocapsules and Hollow Nanoparticles Consisting of Fluorinated Polymer Shells by Interfacial RAFT Miniemulsion Polymerization, Macromol. Chem. Phys. 212(7) (2011) 737-743.

[33] C.H. Ye, Y.W. Luo, X.S. Liu, Synthesis of non-collapsed hollow polymeric nanoparticles with shell thickness on the order of polymer gyration radius, Polymer 52(3) (2011) 683-693.

[34] F. Ishizuka, R.H. Utama, S. Kim, M.H. Stenzel, P.B. Zetterlund, RAFT inverse miniemulsion periphery polymerization in binary solvent mixtures for synthesis of nanocapsules, European Polymer Journal 73 (2015) 324-334.

[35] Y. Luo, H. Gu, A general strategy for nano-encapsulation via interfacially confined living/controlled radical miniemulsion polymerization, Macromol. Rapid Commun. 27 (2006) 21-25.

[36] Y.T. Yu, Q.H. Zhang, X.L. Zhan, F.Q. Chen, Comparison of styrene reversible additionfragmentation chain-transfer polymerization in a miniemulsion system stabilized by 
ammonlysis poly(styrene-alt-maleic anhydride) and sodium dodecyl sulfate, J. Appl. Polym. Sci. 124(5) (2012) 4249-4258.

[37] R. Strickley, Solubilizing Excipients in Oral and Injectable Formulations, Pharm. Res. 21(2) (2004) 201-230.

[38] L.M. Ramirez, J. Babin, A. Durand, J.L. Six, C. Nouvel, Biocompatible dextran-covered nanoparticles produced by Activator Generated by Electron Transfer Atom Transfer Radical Polymerization in miniemulsion, Colloids Surf., A 486 (2015) 60-68.

[39] M. Wu, L.M. Forero Ramirez, A. Rodriguez Lozano, D. Quémener, J. Babin, A. Durand, E. Marie, J.-L. Six, C. Nouvel, First multi-reactive dextran-based inisurf for atom transfer radical polymerization in miniemulsion, Carbohydr. Polym. 130(0) (2015) 141-148.

[40] J. Xia, K. Matyjaszewski, Controlled/"Living" Radical Polymerization. Atom Transfer Radical Polymerization Catalyzed by Copper(I) and Picolylamine Complexes, Macromolecules 32(8) (1999) 2434-2437.

[41] C. Rouzes, M. Leonard, A. Durand, E. Dellacherie, Influence of polymeric surfactants on the properties of drug-loaded PLA nanospheres, Colloids Surf., B 32(2) (2003) 125-135. [42] L. Dupayage, M. Save, E. Dellacherie, C. Nouvel, J.-L. Six, PMMA-grafted dextran glycopolymers by atom transfer radical polymerization, J. Polym. Sci., Part A: Polym. Chem. 46(23) (2008) 7606-7620.

[43] K. Ferji, C. Nouvel, J. Babin, P.-A. Albouy, M.-H. Li, J.-L. Six, Controlled synthesis of new amphiphilic glycopolymers with liquid crystal grafts, J. Polym. Sci., Part A: Polym. Chem. 51(18) (2013) 3829-3839.

[44] L. Dupayage, C. Nouvel, J.-L. Six, Copper mediated ATRP of MMA in DMSO from unprotected dextran macroinitiators, Polym. Bull. 68(3) (2012) 647-655.

[45] L. Dupayage, C. Nouvel, J.-L. Six, Protected versus Unprotected dextran macroinitiators for ATRP Synthesis of Dex-g-PMMA, J. Polym. Sci., Part A: Polym. Chem. 84(1) (2011) 133-134.

[46] M. Manea, A. Chemtob, M. Paulis, J.C. de la Cal, M.J. Barandiaran, J.M. Asua, Miniemulsification in high-pressure homogenizers, AIChE Journal 54(1) (2008) 289-297. [47] https://cameochemicals.noaa.gov, (last visit 20/01/2017).

[48] A. Wade, P. Weller, Handbook of pharmaceutical excipients. , 2nd ed., The Pharmaceutical Press, London, 1994.

[49] J. Raynaud, B. Choquenet, E. Marie, E. Dellacherie, C. Nouvel, J.L. Six, A. Durand, Emulsifying Properties of Biodegradable Polylactide-Grafted Dextran Copolymers, Biomacromolecules 9(3) (2008) 1014-1021.

[50] M.E. Thomson, M.F. Cunningham, Compartmentalization Effects on the Rate of Polymerization and the Degree of Control in ATRP Aqueous Dispersed Phase Polymerization, Macromolecules 43(6) (2010) 2772-2779.

[51] P.B. Zetterlund, Y. Kagawa, M. Okubo, Controlled/living radical polymerization in dispersed systems, Chem. Rev. 108(9) (2008) 3747-3794.

[52] Y. Song, G. Ye, Z.Y. Wang, M. Kopec, G.J. Xie, R. Yuan, J. Chen, T. Kowalewski, J.C. Wang, K. Matyjaszewski, Controlled Preparation of Well-Defined Mesoporous Carbon/Polymer Hybrids via Surface-Initiated ICAR ATRP with a High Dilution Strategy Assisted by Facile Polydopamine Chemistry, Macromolecules 49(23) (2016) 8943-8950.

[53] https://www.drugs.com/pro/copper.html, updated in June 2018, visited august 2018 